\title{
8
}

\section{im

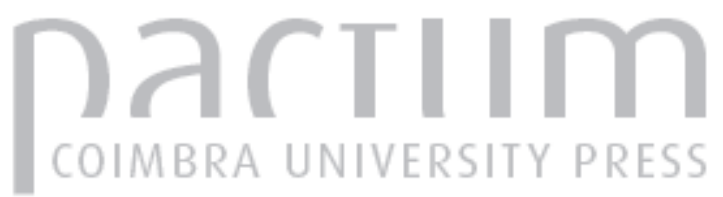

\section{As mulheres nas estruturas de tomada de decisão nos meios de comunicação europeus}

\author{
Autor(es): $\quad$ Ross, Karen
}

Publicado por: Imprensa da Universidade de Coimbra

URL persistente:

URI:http://hdl.handle.net/10316.2/42812

DOI:

DOI:https://doi.org/10.14195/2183-5462_30_4

Accessed : $\quad$ 26-Apr-2023 10:36:53

A navegação consulta e descarregamento dos títulos inseridos nas Bibliotecas Digitais UC Digitalis, UC Pombalina e UC Impactum, pressupõem a aceitação plena e sem reservas dos Termos e Condições de Uso destas Bibliotecas Digitais, disponíveis em https://digitalis.uc.pt/pt-pt/termos.

Conforme exposto nos referidos Termos e Condições de Uso, o descarregamento de títulos de acesso restrito requer uma licença válida de autorização devendo o utilizador aceder ao(s) documento(s) a partir de um endereço de IP da instituição detentora da supramencionada licença.

Ao utilizador é apenas permitido o descarregamento para uso pessoal, pelo que o emprego do(s) título(s) descarregado(s) para outro fim, designadamente comercial, carece de autorização do respetivo autor ou editor da obra.

Na medida em que todas as obras da UC Digitalis se encontram protegidas pelo Código do Direito de Autor e Direitos Conexos e demais legislação aplicável, toda a cópia, parcial ou total, deste documento, nos casos em que é legalmente admitida, deverá conter ou fazer-se acompanhar por este aviso.

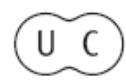


Media Jornalismo Imprensa da Universidade de Coimbra / Coimbra University Press 2 N. 30 Vol. 17, N. . 1 - 2017

\section{MULHERES E MEDIA}




\title{
AS MULHERES NAS ESTRUTURAS DE TOMADA DE DECISÃO NOS MEIOS DE COMUNICAÇÃO EUROPEUS*
}

\author{
WOMEN IN DECISION-MAKING STRUCTURES \\ IN THE EUROPEAN MEDIA
}

\begin{abstract}
KAREN ROSS
University of Liverpool, Department of Communication and Media. L69 3BX, Liverpool United Kingdom
\end{abstract} karen.ross@liverpool.ac.uk

Resumo:

0 reduzido número de mulheres que ocupam altos cargos nas organizações dos media tem sido motivo de preocupação há já várias décadas. Este artigo resume os principais resultados de uma investigação que teve por objetivo analisar e refletir sobre a situação neste domínio na Europa, explorando o grau de entrada das mulheres na gestão a níveis mais elevados num amplo leque de grandes organizações mediáticas, públicas e privadas, da UE e da Croácia. 0 projeto analisou ainda como as mulheres séniores experienciam, de facto, os seus meios-ambientes no local de trabalho e que tipos de igualdade de género e/ou políticas focalizadas nas mulheres estão em vigor nessas organizações. A partir dos dados, o projeto desenvolveu um conjunto de indicadores que seria adotado pelo Conselho da Comissão Europeia e que aqui se apresentam.

\section{Palavras-chave}

O estatuto das mulheres nos media; mulheres e organizações mediáticas; género na tomada de decisão

\section{Abstract}

The small number of women occupying senior positions in media organisations has been a cause for concern for several decades. The article presents the main results of a research aimed to explore women's penetration of top level management across a range of large media organisations, both public sector and privately-owned in the EU and Croatia. The project also analysed how senior women actually experience their media workplace and what kinds of gender-equality and/or women-focused policies are in place in those organisations. From the resulting data the project developed a set of indicators, also presented here, which would be adopted by the Council of the European Commission.

\section{KEYWORDS}

Women's status in media; women and media organisations; gender in decision-making

* Este artigo foi originalmente publicado como: Ross, Karen (2014) “Women in Decision-Making Structures in European Media". In Aimee Vega Montiel, ed. Media and gender: a scholarly agenda for the Global Alliance on Media and Gender. Paris: UNESCO, pp 37-40. Tradução de Maria João Silveirinha. 
INTRODUÇÃO

Como em tantos outros aspetos da vida social, cultural e económica no século XXI, o número das mulheres em cargos de tomada de decisão que trabalham nas indústrias mediáticas é baixo, quando comparado com a sua proporção na força de trabalho do setor. Apesar de existir um crescente número de mulheres que se formam em programas profissionais e profissionalizantes e entram na indústria, a maioria das investigações sugere que elas ficam presas nos quadros médios de gestão e raramente conseguem os cargos cimeiros. Dada a predominância dos estudos norte-americanos neste domínio, a investigação em que este pequeno artigo se baseia tem por objetivo explorar o grau de penetração das mulheres na gestão a níveis mais elevados num alargado leque de grandes organizações mediáticas, públicas e privadas, da UE e da Croácia. 0 trabalho foi financiado pelo Instituto Europeu para a Igualdade de Género e a ideia que lhe deu forma partiu da decisão do Conselho da Presidência da União Europeia no primeiro semestre de 2013 (Irlanda) de dar prioridade à Área J da Plataforma de Ação de Pequim. A área J contempla dois aspetos: um relativo à participação e ao acesso das mulheres na expressão e na tomada de decisões nos e através dos meios de comunicação e das novas tecnologias de comunicação, e outro relativo à promoção de uma representação equilibrada e não estereotipada das mulheres nos media. Embora o projeto tenha abordado ambos os elementos, o presente artigo centra-se exclusivamente no primeiro elemento' ${ }^{1}$.

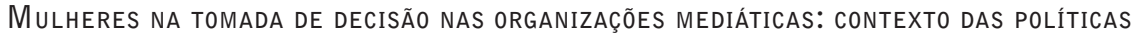

0 reduzido número de mulheres que ocupam altos cargos nas organizações dos media tem sido motivo de preocupação há já várias décadas. Organismos profissionais como a Federação Internacional (e Europeia) de Jornalistas e Mulheres no Jornalismo, ONGs como o Lobby Europeu das Mulheres e os vários Grupos de Trabalho da Comissão Europeia e do Conselho da Europa, realizaram, nos últimos anos, uma série de estudos para explorar esta questão e sugeriram um conjunto de medidas práticas para melhorar e destacar as oportunidades de carreira das mulheres no sector dos media (ver, por exemplo, Comissão Europeia, 2011, Conselho da Europa, 2011). As ações de apoio ao recrutamento e promoção de mais mulheres em cargos séniores no sector dos meios de comunicação social foram complementadas por esforços similares no sentido de permitir que mais mulheres ocupassem os seus lugares nos Conselhos de Administração. A mais recente iniciativa surgiu em Novembro de 2012, quando a Comissão Europeia propôs formalmente uma legislação para acelerar o número de mulheres nesses Conselhos. A diretiva proposta estabelece o objetivo, até 2020, de uma presença de $40 \%$ do sexo menos representado entre as administrações não-executivas de empresas cotadas em bolsa e até 2018 para as organizações de capital público.

1 Os dados e informações utilizados / apresentados foram recolhidos em 2012/2013 no âmbito do Estudo sobre a Área J da Plataforma de Ação de Pequim: As Mulheres e os Meios de Comunicação Social na União Europeia realizada para o Instituto Europeu para a Igualdade de Género sob o contrato EIGE / 2012 / OPER / 07. As opiniões aqui apresentadas são as da autora e não refletem necessariamente a opinião ou posição do Instituto Europeu para a Igualdade de Género. 
Metodologia e Métodos da Investigação

A investigação teve como objetivo explorar até que ponto as mulheres são recrutadas para posições de tomada de decisão nas organizações mediáticas de grande escala em toda a Europa - incluindo os conselhos de administração -, como as mulheres séniores experienciam, de facto, os seus meios-ambientes no local de trabalho e que tipos de igualdade de género e/ou políticas focalizadas nas mulheres estão em vigor nessas organizações. Uma vez analisados os dados resultantes, o projeto pretendia desenvolver um conjunto de indicadores que seria adotado pelo Conselho da Comissão Europeia - ver mais adiante. Foi analisado um total de 99 organizações em todos os Estados-Membros da União Europeia e Croácia, incluindo $39^{2}$ organizações do sector público, 56 empresas de financiamento privado e 4 empresas com financiamento misto. Os critérios de seleção destas últimas incluíram a dimensão da organização (em termos de força laboral), a popularidade do serviço/produto (por exemplo, as audiências de televisão e rádio, a circulação dos jornais) e a sua importância (por exemplo, em termos de formação da opinião pública).

Na maioria dos países, foi necessário tomar decisões com base em vários critérios - por exemplo, quando um jornal tinha uma circulação elevada, mas uma força laboral reduzida, ou onde várias estações de televisão reclamavam ter as maiores audiências, mas onde os dados verificáveis sobre estas eram impossíveis de obter. Dentro da amostra para cada país, o serviço público de radiodifusão foi sempre incluído e, em seguida, inquiriram-se até três organizações privadas, consoante a densidade mediática nacional. Na maioria dos países, os meios de comunicação privados selecionados incluíam pelo menos um jornal e pelo menos uma estação de TV: as estações de rádio foram incluídas em países onde a rádio era particularmente popular, ou em países de alta densidade mediática, ou onde o serviço público de radiodifusão dividia a TV e rádio em duas estruturas operacionais separadas.

\section{Resultados}

"Se a seleção [de candidaturas] se basear quase exclusivamente numa relação política, as mulheres são em geral desfavorecidas no que diz respeito às posições de topo; quando a seleção se baseia nos currículos e na qualidade do trabalho, a questão muda completamente". (Maria, emissora de serviço público)

Os resultados revelam alguns dados interessantes relativos ao alcance provável das ambições da Plataforma de Pequim no que se refere às "mulheres e media".

Ainda que se trate de um inquérito de pequena dimensão com uma amostra de 99 organizações, elas compreendem todas as empresas de radiodifusão de serviço público (39 organizações distintas) na UE e na Croácia e as 56 organizações privadas constituem algumas das principais empresas de comunicação europeias, tendo, a maioria delas, empresas-mãe internacionais. As quatro organizações com financia-

2 Existem aqui 39 organizações do sector público porque alguns países desagregam a televisão da rádio e também porque a Bélgica tem duas organizações do sector público que transmitem em francês e flamengo, respetivamente. 
mento misto (público e privado) também são grandes organizações no campo dos media. Assim, embora não reclamemos uma grande representatividade da amostra, sugerimos que os resultados não são certamente atípicos das grandes organizações de comunicação social e fornecem, pelo menos, um retrato instantâneo da paisagem mediática europeia. 0 resultado mais problemático, como se vê no quadro abaixo, é o baixo número de mulheres que ocupam altos cargos na tomada de decisão ou têm assento nos Conselhos de Administração: apenas 1037 posições num total de 3376 (30\%) eram ocupadas por mulheres.

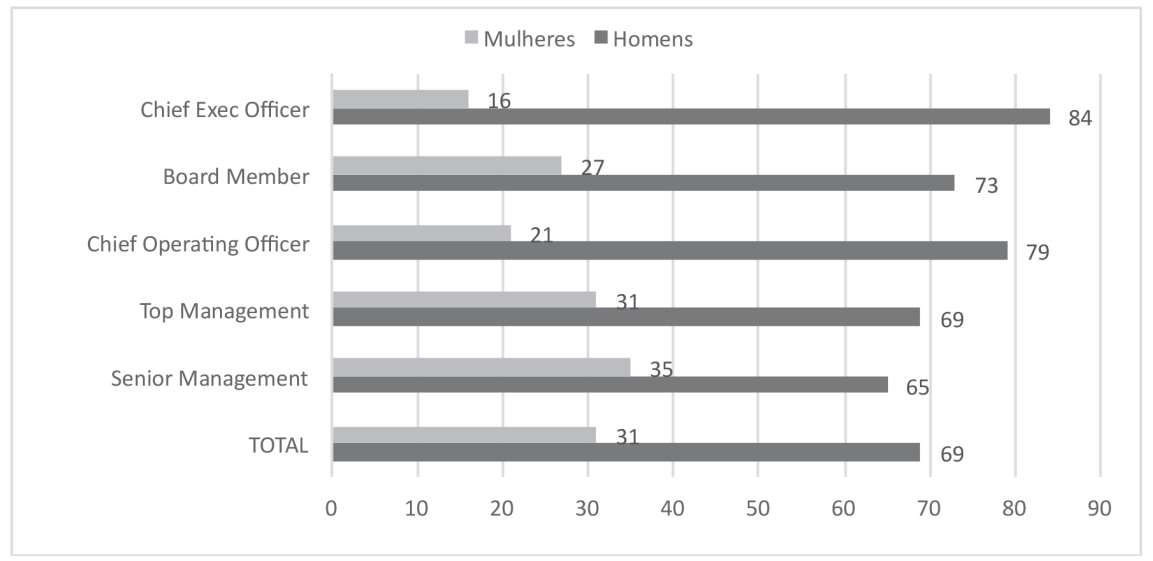

Quadro: Percentagem de mulheres e homens em posições de tomada de decisão e em Conselhos de Administração de 99 grandes organizações dos media na UE27 + Croácia

Cerca de um terço de todas as posições que temos nos serviços públicos de radiodifusão e cerca de um quarto dos cargos no sector privado são ocupados por mulheres. 0 setor de radiodifusão de serviço público e as organizações com financiamento misto surgem com muito mais probabilidade de nomear mulheres para papéis séniores (59\%) do que as organizações privadas (41\%). As conclusões mostram que, em alguns países, as mulheres estão presentes em números relativamente elevados, tanto a nível estratégico como operacional, em relação à média da UE-27. Poderá haver uma série de razões para essas contra-tendências, sendo uma delas o facto de algumas organizações terem sido pró-activas nos seus esforços para aumentar as oportunidades para as mulheres, tanto em termos de políticas, como em termos de práticas e promoção de emprego, assegurando um processo transparente baseado no mérito e na competência.

Por outro lado, os problemas políticos em alguns países significaram que "apenas" ficaram mulheres a gerir organizações mediáticas e que, com o decorrer dos tempos, os homens não regressaram, e em vez disso, passaram para setores mais "prestigiantes". No que diz respeito aos planos de igualdade de género, políticas e códigos de diversidade, apenas menos de metade das organizações inquiridas têm algum tipo de política de igualdade que, pelo menos, mencione o género, embora menos de uma em cada cinco organizações tenha uma política explicitamente focada no género. Um número semelhante tem mecanismos formais para monitorizar as suas políticas de género e/ou de igualdade e nove organizações têm um Departa- 
mento de Igualdade ou Diversidade. No que se refere às medidas práticas, a medida mais frequentemente referida diz respeito ao assédio sexual e menos de $25 \%$ das organizações mencionaram esta situação, seguidas de uma política de dignidade no trabalho (19\%) e de licenças de maternidade (17\%). Apenas seis organizações apoiam programas de formação estruturados para mulheres, embora um pouco mais (nove por cento) ofereçam formação de consciencialização da igualdade para o seu pessoal. Em termos de diferenças sectoriais, os organismos de radiodifusão do serviço público tenderam de forma mais significativa a desenvolver estruturas formais de género e igualdade do que as organizações do sector privado.

MuLHERES NA TOMADA DE DECISÃO NAS PRINCIPAIS ORGANIZAÇõeS MEDIÁTICAS - TRÊS INDICADORES

Os indicadores abaixo indicados medem a participação das mulheres (e dos homens) nas estruturas de decisão das principais organizações mediáticas dos Estados-Membros da UE e da Croácia, bem como a inclusão das mulheres nos conselhos de administração dessas organizações e a existência de códigos e medidas destinadas a incentivar o desenvolvimento das carreiras das mulheres.

\section{INDICADOR 1}

Este indicador monitoriza a proporção de mulheres e homens nos cargos executivos de tomada de decisão numa série de funções de gestão e operacionais, incluindo: Direção Executiva, Direção Operacional, (por exemplo, Direção-Geral, Chefia de Edição, Gestão Operacional aos níveis de topo e séniores.

\section{INDICADOR 2}

Este indicador fornece informações sobre a proporção de mulheres e homens nas direções importantes de tomada de decisão que governam as organizações mediáticas, incluindo os conselhos de supervisão externos mais relevantes (seja da organização ou da sua empresa-mãe), responsáveis pela direção estratégica de cada organização mediática, por exemplo Conselho de Administraçã̃o ou o Conselho de Gestão.

\section{INDICADOR 3}

Este indicador é relativo à existência de políticas, incluindo as relacionadas com: igualdade de género, igualdade de oportunidades / diversidade; assédio sexual ou dignidade no trabalho; licença parental; mecanismos de implementação e monitorização da igualdade de género, tais como comités e oficiais; e medidas práticas destinadas a apoiar o desenvolvimento das carreiras das mulheres, tais como formação em liderança / gestão para mulheres; formação em matéria de sensibilização para a igualdade do pessoal; regimes de trabalho flexível.

\section{Conclusões}

"Se estivermos cercadas por homens, tendemos a assumir os seus padrões, regras e agendas como norma. E, acreditem, estas seriam diferentes em equipes mistas. "(Katharina: jornal privado).

"Se uma mulher estiver realmente determinada a atravessar a fronteira para áreas "masculinas" ... ela tem de se ajustar, pelo menos em parte, às regras do "Clube dos homens ". (Erzebet, jornal privado) 
As mulheres continuam a estar sub-representadas nas estruturas de tomada de decisão das principais organizações de comunicação social, tanto a nível operacional como enquanto gestoras séniores e em níveis estratégicos, como enquanto CEOs e membros do conselho de administração. É importante salientar que os resultados deste estudo sugerem que não existe uma ligação clara entre a existência de políticas de género ou de diversidade ou de igualdade nas organizações e um elevado número de mulheres em posições de tomada de decisão: por vezes, as duas coisas andavam a par e, noutros casos, não. Isso acontece sobretudo porque sem que as políticas sejam monitorizadas ativamente, sem haver análises da força de trabalho e sem 0 desenvolvimento de planos de ação, as políticas permanecem ao nível de papel, mas não da prática. Os depoimentos de muitas das mulheres séniores entrevistadas deixaram claro que o contexto cultural, em diferentes níveis de uma organização, tem um impacto significativo sobre as perspetivas de carreira das mulheres. Por outras palavras, um ambiente de trabalho que reconheça o valor da contribuição das mulheres e reconheça as suas diferentes responsabilidades familiares e assistenciais é tão importante quanto a existência de políticas formais de igualdade. No entanto, a manifestação mais óbvia do compromisso de uma organização para com a igualdade de género é o desenvolvimento de um quadro formal de políticas de igualdade que inclua mecanismos de monitorização, avaliação e ação. Isto é importante em termos estruturais, mas também para dar um sinal claro a todos/as os/as funcionários/as de que as questões de igualdade são levadas a sério. Tal é parte do contexto cultural de qualquer organização, sendo crucial para determinar o seu ethos operacional, mas também, de modo importante, o que passa a ser visto como as suas normas comportamentais.

Registámos com muito agrado que o Conselho da União Europeia adotou os indicadores que elaborámos em Junho de $2013^{3}$, embora 0 que acontecerá a seguir seja difícil de prever. As mulheres são, em grande parte, negligenciadas para promoção por razões que não são da sua competência, incluindo o seu género (discriminação em razão do sexo) e a sua (in)flexibilidade para assumir novas oportunidades devido às suas responsabilidades domésticas e / ou familiares (discriminação em razão da família ou do cuidado). Por vezes, as mulheres optam por dar prioridade à família em detrimento da carreira, mas isso acontece com frequência porque as culturas de trabalho tornam impossível alcançar um equilíbrio entre a vida profissional e a vida familiar que beneficie tanto a pessoa quanto a organização empregadora. Grande parte da literatura sobre género e media, assim como as profissionais séniores entrevistadas para este estudo, deixam claro que o contexto cultural em que as mulheres trabalham é parte do problema, mas também pode ser uma grande parte da solução, pelo que incentivar a gestão de topo a levar a sério a igualdade de género é bom para o corpo de funcionários e, como estudos recentes sobre desempenho profissional mostram, bom para as empresas (BiS, 2011; CED, 2012; McKinsey \& Co, 2012).

3 http://www.consilium.europa.eu/uedocs/cms_data/docs/pressdata/en/lsa/137546.pdf 
Bibliografia

Department for Business, Innovation and Skills (2011) Women on Boards. London: BiS.

Committee for Economic Development (2012) Fulfilling the Promise: How More Women on Corporate Boards Would Make America and American Companies More Competitive. CED: Washington DC.

McKinsey \& Company (2012) Women Matter 2012: Making the Breakthrough. McKinsey \& Co. http://www.mckinsey.com/client_service/organization/latest_thinking/women_matter. Accessed 15 November 2012.

Gorpe, S., Petersone, B. and Walker, G., (2012) "Feminisation of the Public Relations/Communications Profession in Europe: Initial Findings: Where Are Women in Public Relations Academia and in the Professional World?" Paper presented to the EUPRERA conference, Istanbul, September.

European Commission Advisory Committee on Equal Opportunities for Women and Men (2010) Opinion on "Breaking gender stereotypes in the media". Brussels: European Commission.

Council of Europe, Steering Committee for Equality between Women and Men (2011) Women and Journalists First. Geneva: CDEG.

Karen Ross - é professora de Género e Media da Universidade de Newcastle. 0 seu ensino e pesquisa focam as questões de género, media e sociedade, incluindo aspetos de dos media sociais, comunicação pública e política. Faz parte do conselho editorial de várias revistas internacionais.

Artigo por convite /Article by invitation 